\title{
RESEARCH
}

Open Access

\section{Genetic variation of aldolase from Korean isolates of Plasmodium vivax and its usefulness in serodiagnosis}

Jung-Yeon Kim ${ }^{1 \dagger}$, Hyung-Hwan Kim²,4†${ }^{2, \text { Hyun-II Shin }}{ }^{1}$, Youngjoo Sohn ${ }^{3}$, Hyuck Kim ${ }^{4}$, Sang-Wook Lee ${ }^{5}$, Won-Ja Lee ${ }^{1 *+}$ and Hyeong-Woo Lee L*t $^{*}$

\begin{abstract}
Background: The malaria aldolase is widely used as rapid diagnostic test (RDT), but the efficacy in aspect of its serological effectiveness in diagnosis is not known. The genetic variation of Korean isolates was analysed and recombinant aldolase was evaluated as a serological antigen in Plasmodium vivax malaria.

Methods: Genomic DNA was purified and the aldolase gene of $P$. vivax from 25 patients' blood samples was amplified. The samples came from 5 epidemic areas; Bucheon-si, Gimpo-si, Paju-si of Gyeonggido, Gangwha-gun of Incheon metropolitan city, and Cheorwon of Gangwon-do, South Korea. The antigenicity of the recombinant aldolase was tested by western blot and enzyme-linked immunosorbent assay (ELISA).

Results: Sequence analysis of 25 Korean isolates of $P$. vivax showed that the open reading frame (ORF) of 1,110 nucleotides encoded a deduced protein of 369 amino acids (aa). This ORF showed 100\% homology with the P. vivax Sal I strain (XM_00165894) and P. vivax WDK strain (AF247063), 87.4\% homology with Plasmodium falciparum (AF179421), 90.6\% homology with Plasmodium chabaudi (AF247060), 89.5\% homology with Plasmodium vinckei (AF247061), and 96.7\% homology with Plasmodium knowlesi. A single nucleotide polymorphism (SNP) at nucleotide 180 ( $\mathrm{G}$ to $\mathrm{A}, \mathrm{n}=5$ ) was also observed in the isolates. The expressed recombinant protein had a molecular weight of approximately $31 \mathrm{kDa}$ (monomeric form) and $62 \mathrm{kDa}$ (dimeric form) as analysed by sodium dodecyl sulfatepolyacrylamide gel electrophoresis (SDS-PAGE) analysis. Among 109 P. vivax patients, 32 (29.4\%) had positive in an enzyme-linked absorbance assay (ELISA). This result showed significant correlation between ELISA and an indirect fluorescent antibody test (IFAT) $(P<0.0001)$.

Conclusions: The aldolase gene from Korean isolates of $P$. vivax showed one SNP at nucleotide position 180; this SNP mutant was discovered in only the western part of Han River, and included the regions of Ganghwa, Gimpo, and Bucheon. Based on the results, the relationship between antibody production against aldolase and the pattern of disease onset should be more investigated before using aldolase for serodiagnosis.
\end{abstract}

\footnotetext{
*Correspondence: wonja@nih.go.kr; rainlee67@yahoo.co.kr

'Equal contributors

'Division of Malaria and Parasitic Diseases, National Institute of Health, Korea

Centers for Disease Control and Prevention, Cheongwon-gun 363-951,

Republic of Korea

${ }^{5}$ Department of Pathology, University of Florida, J-566, 1275 Center Drive,

Gainesville, FL 32610, USA

Full list of author information is available at the end of the article
}

\section{Biomed Central}

(c) 2012 Kim et al.; licensee BioMed Central Ltd. This is an Open Access article distributed under the terms of the Creative Commons Attribution License (http://creativecommons.org/licenses/by/2.0), which permits unrestricted use, distribution, and reproduction in any medium, provided the original work is properly cited. 


\section{Background}

Microscopic examination of the Plasmodium species is regarded as the gold standard method for malaria diagnosis. Despite the simplicity and low cost, it is not always available [1]. Over the last ten years, the development of alternative diagnostic tests for malaria, such as rapid diagnostic tests (RDTs), has made it possible to extend biological diagnosis to remote areas with few resources. These lateral-flow immunochromatographic tests detect specific antigens produced by malaria parasites and are rapid and simple to carry out without electricity, specific equipment or intensive training [2-4].

To detect Plasmodium, monoclonal antibodies against lactate dehydrogenase ( $\mathrm{pLDH})$, histidine-rich protein-2 (HRP-2) and aldolase are widely used [5,6]. The genetic diversity of HRPII is known to partly influence the sensitivity of RDT [7]. It is known that the genetic variation of aldolase genes is very low $[8,9]$, but it is not clear if this is true in the Korean isolates of Plasmodium vivax. Aldolase is a key enzyme that helps convert glucose into energy in malaria parasites. Meier et al found that two type of aldolase, aldo-1 and aldo-2, from Plasmodium berghei. aldo-1 of $P$. berghei was found to be virtually identical to the aldolase gene of Plasmodium falciparum, whereas aldo- 2 had $13 \%$ sequence diversity. In addition, aldo- 1 was detected in the sporozoite stage while aldo-2 was detected in the asexual stages of malaria parasites with specific antibody probes [10].

In this study, it was investigated that genetic variation of aldolase genes which were isolated from 25 patients who lived in 5 geographically different epidemic areas in South Korea and evaluated the recombinant protein as a serodiagnostic tool.

\section{Methods}

\section{Blood sample collection}

Patients with clinically suspected malaria attending the Public Health Centres in Gangwha-gun, Gimpo-si, Bucheon-si, Paju-si of Gyeonggi-do and Cheorwon-gun of Gangwon-do, South Korea in 2011, were examined for malaria parasites. Approximately $3 \mathrm{ml}$ of blood was collected from each symptomatic patient. Thin and thick blood smears were prepared for microscopic examination (magnification $7 \times 100$ ). Blood samples were transported to the Korean National Institute of Health $(\mathrm{KNIH})$, where sera were separated and stored at $-20^{\circ} \mathrm{C}$ for future antibody analysis. Informed consent was obtained from all patients, and all samples were collected under human use protocols that have been reviewed and approved by the Human Ethics Committee of the National Institute of Health (Osong, Korea).

\section{Amplification of the aldolase gene}

For the purpose of expression of the aldolase gene, genomic DNA was extracted from the whole blood of a malaria patient using a QIAamp Blood Kit (Qiagen, Hilden, Germany). PCRs were performed using AccuPower PCR Premix (Bioneer, Taejeon, Korea), 50 ng of purified genomic DNA, 40 pmoles each of forward (AF1; 5'- GCC ACT GGA TCC GAA TAT AAA AAC GCC CCC-3') and reverse primers (AR1; 5' - ATA GAC GTA CTT CTT TTC GTA AAG GGA TGC-3') and the total volume was adjusted to $20 \mathrm{ml}$ with distilled water. The thermocycler conditions were as follows: denaturation at $94^{\circ} \mathrm{C}$ for $5 \mathrm{~min}$, 35 cycles of $1 \mathrm{~min}$ at $94^{\circ} \mathrm{C}, 1 \mathrm{~min}$ at $55^{\circ} \mathrm{C}$ and $2 \mathrm{~min}$ at $72^{\circ} \mathrm{C}$, and finally incubation at $72^{\circ} \mathrm{C}$ for $5 \mathrm{~min}$. All of the PCR products were analysed on a $1.2 \%$ agarose gel, confirmed under a UV transilluminator and purified with a NucleoSpin Extract Kit (Macherey-Nagel, Duren, Germany). The purified PCR products were ligated with pCR2.1 cloning vector (Invitrogen, Carlsbad, CA, USA) and then transformed into Escherichia coli INVa F' according to the procedures of Invitrogen.

\section{DNA sequencing and analysis}

The PCR product inserted into E. coli was selected for on ampicillin and X-gal containing medium. To confirm the transformants, gel electrophoresis was performed with EcoRI digestion products after preparation of the plasmid with a Qiagen plasmid isolation kit, according to the protocol supplied by the manufacturer. The aldolase gene sequence was determined using ABI PRISM dye terminator cycle sequencing ready reaction kit FS (Perkin Elmer, Cambridge, MA, USA) according to the supplied manual. M13 reverse and M13 forward $(-20)$ primers were used in sequencing. Nucleotide and deduced amino acid sequences were analysed using EditSeq and Clustal in the Megalign program, a multiple alignment program in the DNASTAR package (DNASTAR, Madison, WI, USA). The internet-based BLAST search program of the National Centre for Biotechnology Information (NCBI) was used to search protein databases. The gene sequences of aldolase from the Korean isolates were deposited in GenBank (Accession No. JN181172-JN181196).

\section{Construction of the aldolase expression vector}

For the expression of aldolase gene of Pv Kor12 type strain in E. coli, the gene fragment was amplified from the DNA of blood samples that were confirmed to be infected with $P$. vivax as described above, and which have the SmaI and SalI sites on their $5^{\prime}$ ends. Amplified PCR products were digested with SmaI and SalI, purified with a Qiagen Gel Extraction Kit after being run on an agarose gel and were then integrated into the SmaI and SalI cleavage sites of the pQE80 expression vector (Qiagen). The resulting plasmid was subsequently used for the expression of the aldolase fusion protein in E. coli DH5a [11]. Transformants were confirmed both 
by gel electrophoresis of plasmid DNA after restriction enzyme digestion with SmaI and SalI.

\section{Expression and purification of recombinant aldolase}

Expression of the recombinant protein was induced in E. coli with isopropyl-1-thio- $\beta$-D-galactopyranoside (IPTG) [12]. $1 \mathrm{mM}$ IPTG was added to cultures of $E$. coli DH5 $\alpha$ (pVKor12) grown to a logarithmic phase in liquid LB containing $100 \mu \mathrm{g} / \mathrm{ml}$ ampicillin and $25 \mu \mathrm{g} / \mathrm{ml}$ kanamycin to induce expression of the target protein and purification of the aldolase fusion protein was carried out using immobilized metal ion affinity chromatography [13]. The purification was done under native conditions according to the supplier's protocol (Qiagen). Proteins were analyzed on sodium dodecyl sulfate-polyacrylamide gel electrophoresis (SDS-PAGE) in each purification step.

\section{Western blot analysis}

Recombinant aldolase fusion protein was separated on a $12 \%$ SDS-PAGE gel and was then transferred to a nitrocellulose membrane. After the transfer, the membrane was cut into strips and blocked for non-specific binding with $5 \%$ skim milk for $12 \mathrm{hrs}$ at $4^{\circ} \mathrm{C}$. The membrane was then washed in PBS with $0.15 \%$ Tween 20 for $3 \times 10 \mathrm{~min}$. The strips were allowed to react with sera of malaria patients or of uninfected people (diluted 1:100, vol/vol) for $4 \mathrm{hrs}$ and then washed using the procedure described above. The membrane was then incubated with diluted peroxidase-conjugated goat anti-human IgG secondary antibody $(1: 1,000, \mathrm{v} / \mathrm{v})$ (Sigma) for $3 \mathrm{hrs}$ at room temperature. For colour development, a solution containing $0.2 \%$ diaminobenzidine and $0.02 \% \mathrm{H}_{2} \mathrm{O}_{2} / \mathrm{PBS}$ was applied to each well $[14,15]$.

\section{Enzyme-linked immunosorbent assay}

Sera from patients infected with $P$. vivax were analysed for the presence of antigen-specific antibody using 96-well plates coated with $0.5 \mathrm{mg} / \mathrm{ml}$ purified recombinant protein that had been expressed in E. coli and dissolved in phosphate-buffered saline (PBS, $\mathrm{pH} 7.4$ ) overnight at $4^{\circ} \mathrm{C}$. Malaria patient serum was diluted 1:100 (v/v) in blocking buffer $(0.25 \%$ PBS-Tween 20 with $1 \%$ bovine serum albumin, $\mathrm{pH}$ 7.4) and incubated for $1 \mathrm{hr}$, followed by incubation with peroxidase-conjugated goat anti-human IgG secondary antibody at a 1:1,000 dilution (v/v, Sigma). Optical density was measured with a spectrophotometer at $405 \mathrm{~nm}$ (Molecular Devices, Sunnyvale, CA) [15]. It was regarded as positive sera showed over the cut off value which obtained by mean $\pm 2 \mathrm{X}$ standard deviation (SD) of negative controls.

\section{Indirect fluorescent antibody test}

To test for antibodies against malaria, indirect fluorescent antibody test (IFAT) was performed using the whole blood antigen for P. vivax [16-18]. Briefly, $10 \mathrm{ml}$ of malaria parasite-infected blood was collected by venopuncture from $P$. vivax patients. After plasma removal, the blood cells were suspended in phosphate buffered saline (PBS, $\mathrm{pH} \mathrm{7.2)}$ and centrifuged for $5 \mathrm{~min}$ at $2,500 \mathrm{rpm}$. The supernatant was discarded and the cells were resuspended in fresh PBS. This wash step was repeated three more times, and then an appropriate amount of PBS was added to maintain the parasitaemia at no less than $1 \%$. Cells were added to each well contained in Teflon coated slides. After $12 \mathrm{hrs}$ drying at room temperature, the slides were stored at $-70^{\circ} \mathrm{C}$. In order to determine the antibody titres against $P$. vivax for each patient, the antigen slides were fixed in pre-cooled acetone $\left(-20^{\circ} \mathrm{C}\right)$ for $10 \mathrm{~min}$, washed with PBS, and then $20 \mu \mathrm{l}$ of diluted sera, 1:32 to $1: 8,192$ ( $\mathrm{vol} / \mathrm{vol})$, was added to each well. Positive and negative controls were also spotted onto each slide and then the slide was incubated in a humidified chamber for $30 \mathrm{~min}$ at $37^{\circ} \mathrm{C}$. The reactions on the slides were quenched by washing the reacted sera with PBS for $6 \mathrm{~min}$, and then the slides were dried at room temperature. Diluted FITC conjugated antihuman IgG (Sigma, 1:32 vol/vol in PBS) was added to each well and then the slides were incubated and washed using the same method described above. Several drops of buffered glycerol were added to the samples, and then coverslips were applied. The slides were examined under the $40 \mathrm{x}$ objective of a fluorescence microscope.

\section{Data analysis}

The relationship between ELISA and IFAT positive rate was analyzed by one-way ANOVA. Data analyses were performed using GraphPad (GraphPad Software, Inc., La Jolla, CA, USA).

\section{Results}

Blood collection and sequence variation of aldolase from Korean isolates of Plasmodium vivax

The geographical locations of study areas were expressed in Figure 1. Gangwha-gun, Gimpo-si, and Bucheon-si are located along the western part of Han River, which is the largest river that passes through Seoul, South Korea. Paju-si and Cheorwon-gun are located along the eastern part of Han River. Five blood samples infected with indigenous $P$. vivax were collected from each city in 2011. Among 25 Korean isolates of aldolase, 12 isolates had the same DNA and amino acid sequences as $P$. vivax Sal-1 (XM_001615894) and these were designated as strain type Pv Kor12. The aldolase from these isolates had 1110 nucleotides and 386 amino acids. When the amino acid of Pv Kor12 was compared with several Plasmodium species, Pv Kor12 showed $100 \%$ homology with P. vivax WDK (AF247063, 1110 bp), 87.4\% homology with P. falciparum (AF179421, 1089 bp), 90.6\% homology with $P$. chabaudi (AF247060, $1054 \mathrm{bp}$ ), 89.5\% homology with $P$. vinckei 


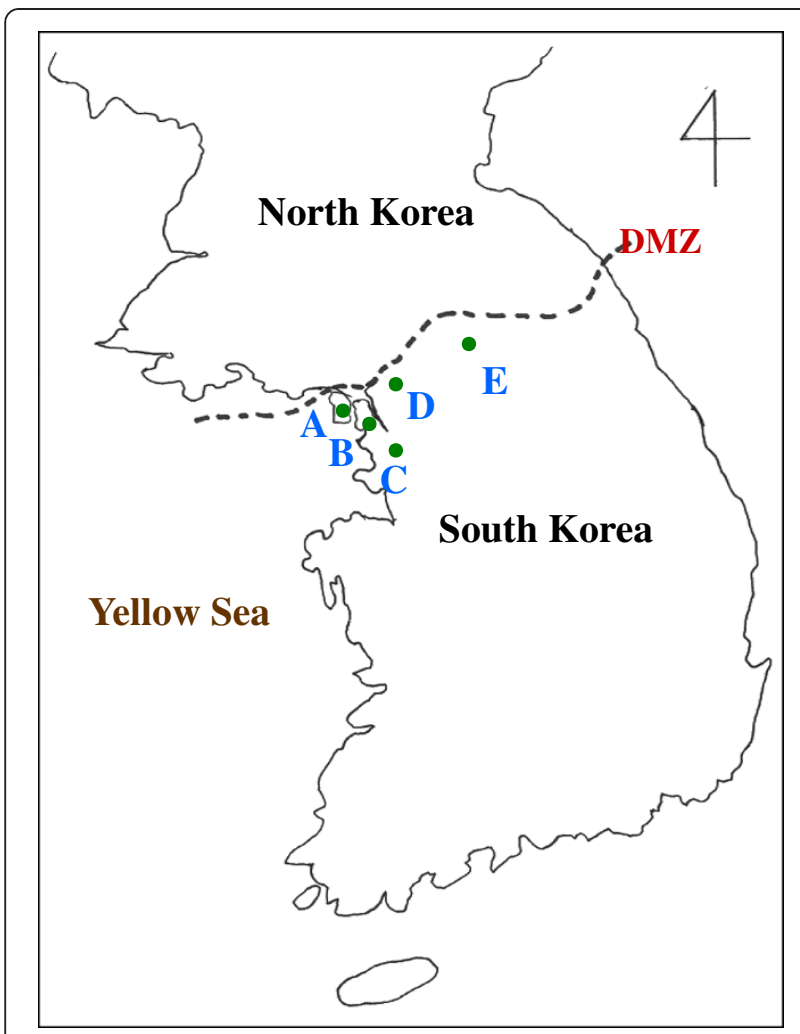

Figure 1 Studied areas. A; Ganghwa-gun, B; Gimpo-si, C; Bucheon-si, D; Paju-si, E; Cheorwon-gun. DMZ; demilitarized zone.
(AF247061, $1054 \mathrm{bp)}$ ), and 96.7\% homology with P. knowlesi (XM_002260389, 1170 bp) (Figures 2 and 3).

The aldolase gene was amplified from the genomic DNA of 25 Korean isolates. Amplification of the aldolase gene yielded a product of approximately 1,100 base pairs. After purification, the DNA fragment was ligated into the pCR 2.1 cloning vector $(3.9 \mathrm{~kb})$. The plasmid containing the PCR product was named pValdol $(5.0 \mathrm{~kb})$ and was used for DNA sequence analysis. Based on DNA sequencing, the cloned aldolase gene was shown to be $1,110 \mathrm{bp}$ and consisted of 386 amino acids that were deduced by DNASIS. One synonymous single nucleotide polymorphism (SNP) at base pair $180(\mathrm{n}=5)$, from $\mathrm{G}$ to $\mathrm{A}$, was observed based on literatures $[6,8]$. Two of SNP were from Gangwha-gun, one from Gimpo-si, two from Bucheon-si, and none were from Paju-si or Cheorwon-gun (Figure 4). Rest of them $(n=8)$ has one or two SNPs, but those locations did not show any common feature. These should be cleared through the analysis of the more DNA samples.

\section{Expression of aldolase in $E$. coli}

The resultant plasmid pVKor12 contained the aldolase gene fused to a (His) ${ }_{6}$-tag (Figure 5A). The recombinant plasmid pVKor12 was then transferred into E. coli DH5 $\alpha$. As analysed on SDS-PAGE followed by Coomasie blue staining, two forms of recombinant aldolase protein were observed under native purification conditions, a dimeric form $(62 \mathrm{kDa})$ and a monomeric form (31 kDa) (Figure 5B).

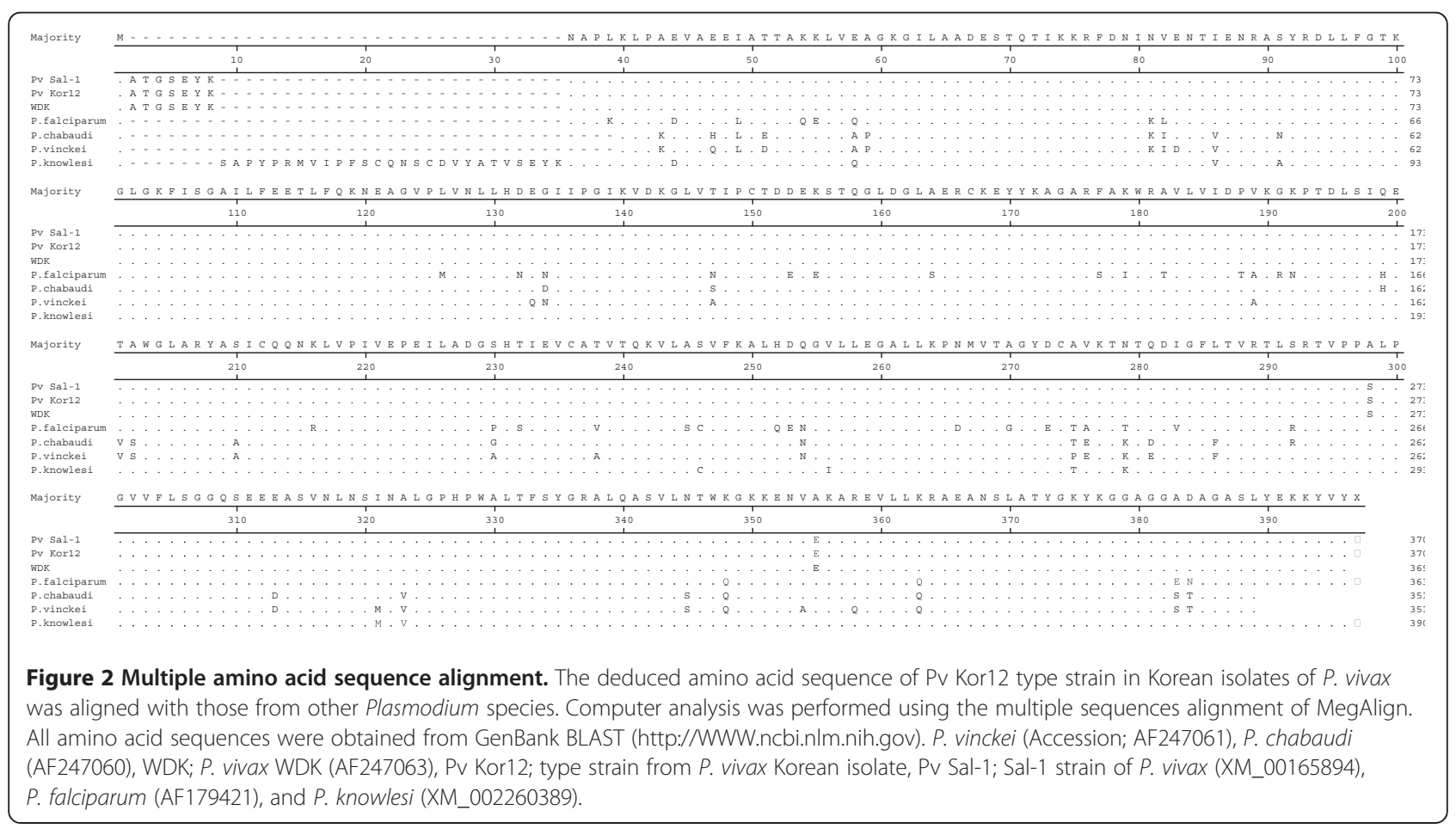




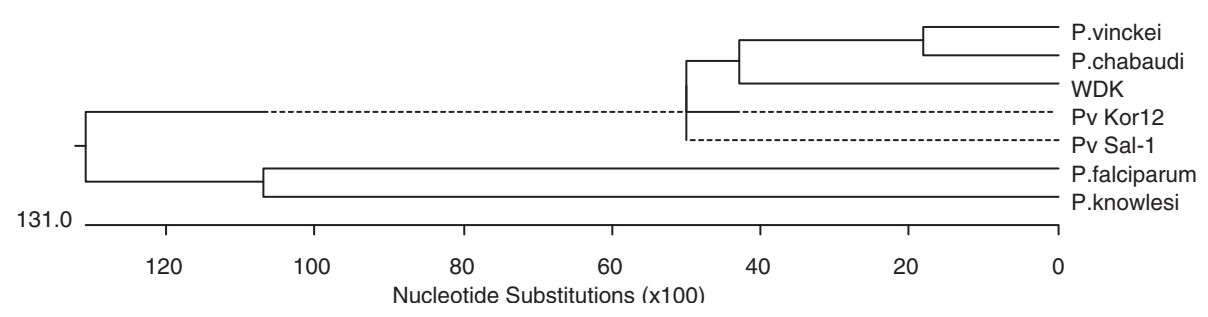

Figure 3 Phylogenetic relationships between the aldolase genes of several strains of Plasmodium. Computer analysis was performed using the multiple sequences alignment of MegAlign. All amino acid sequences were obtained from GenBank BLAST (http://WWW.ncbi.nlm.nih.gov). P. vinckei (Accession; AF247061), P. chabaudi (AF247060), WDK; P. vivax WDK (AF247063), Pv Kor12; Type strain of from P. vivax Korean isolate, PV Sal-1; Sal-1 strain of P. vivax (XM_00165894), P. falciparum (AF179421), and P. knowlesi (XM_002260389).

\section{Antigenicity of the aldolase recombinant protein}

To determine the antigenicity of the aldolase recombinant protein by western blot, ELISA, and IFAT, sera of malaria patients which had been reserved in KNIH collected between 2009 and 2010. Negative sera were collected from volunteers of stuffs in KNIH. Sera of twelve malaria patients showed positive reaction by western blot while the sera from the normal control group $(n=7)$, who had never been exposed to malaria, tested negative (Figure 6).
After the number of malaria patients was increased, the antigenicity of recombinant aldolase was evaluated by ELISA. Thirty-two of 109 sera (29.4\%) from malaria patients, as confirmed by microscopic analysis, reacted with the aldolase recombinant antigen. In addition, 3 of 67 normal persons $(4.5 \%)$ reacted with the aldolase recombinant antigen (Figure 7). The reaction intensity of the recombinant aldolase antigen with patient sera increased significantly depends on the positive reactions of each serum dilution

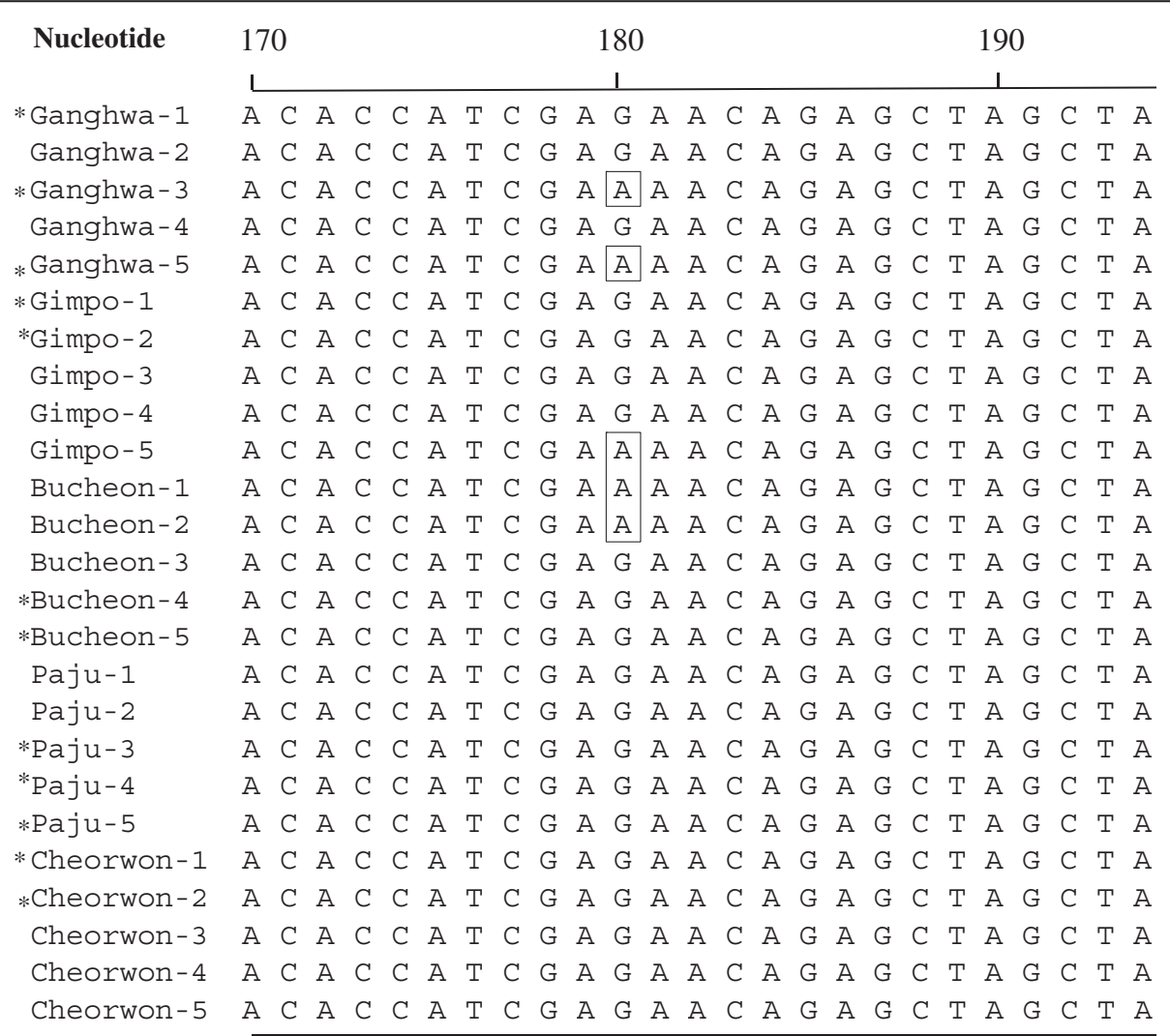

Figure 4 Comparing the single nucleotide polymorphism (SNP) of the aldolase gene between 25 Plasdodium vivax Korean isolates. *; represents the isolate belong to PvKor12. All amino acid sequences were deposited in GenBank BLAST (http://WWW.ncbi.nlm.nih.gov, Accession No. JN181172-JN181196). 

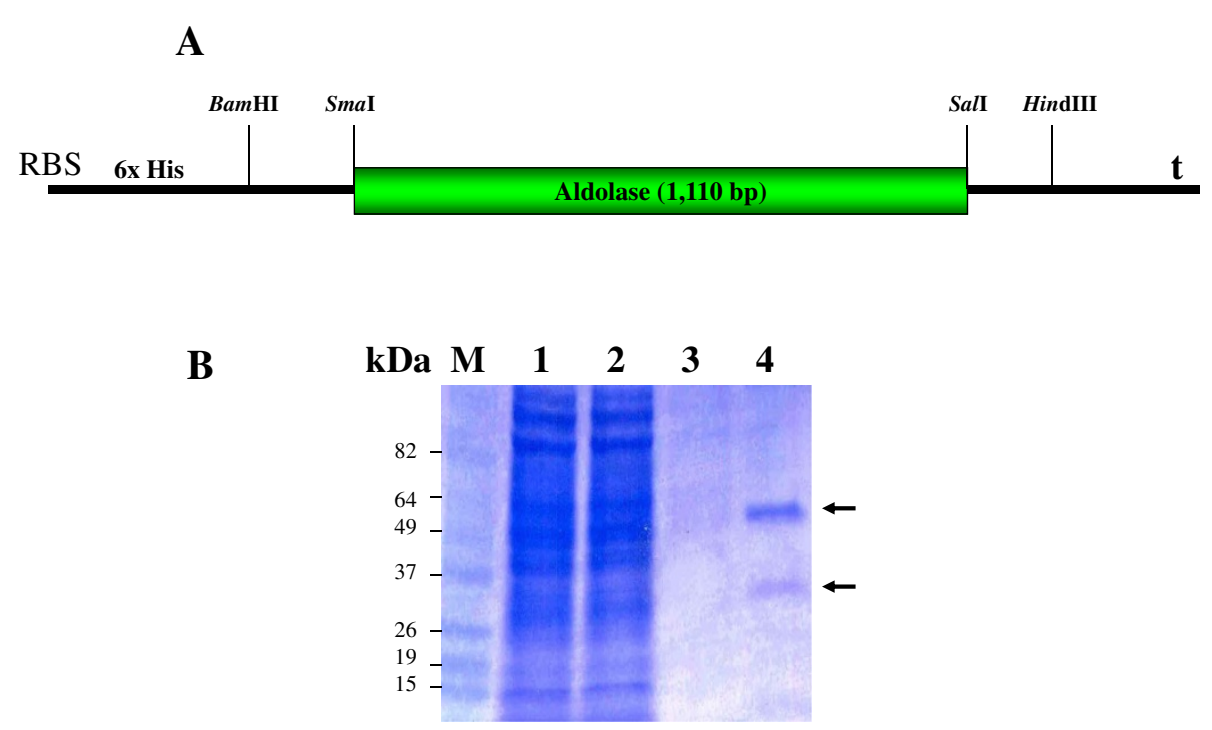

Figure 5 Gene structure for the expression of Pv aldolase (A). Patterns of purified aldolase by SDS-PAGE under native conditions using Ni-NTA agarose resin (B). Lane 1: Crude cell lysate, Lane 2: Flow-through, Lane 3: 20 mM imidazole wash, Lane 4: 250 mM imidazole elution, Lane M: Protein size marker. RBS: ribosome binding site, 6 xHis: $6 x$ Histidine tag sequence, t: stop codon.

in IFAT (Figure $8, P<0.0001$ ). The intensity of ELISA reached a maximum level at a 1:512 serum dilution of IFAT.

\section{Discussion}

Aldolase is an important enzyme involved in the glycolysis pathway of malaria parasites. Higher vertebrates usually has three kind of tissue-specific aldolase isoenzymes [19], however, P. falciparum and P. vivax posses only one aldolase isoenzyme [20,21], similar to Trypanosoma brucei [22]. The aldolase enzymes of P. falciparum and $P$. vivax are both 369 amino acids long and their nucleotide and amino acid sequences are relatively conserved than other genes' variation [21]. However, genetic variation of the aldolase gene of Korean isolates is not analysed systematically. Therefore, it is important to understand the genetic variation of the aldolase gene in Korean isolates.
For the $110 P$. vivax aldolase gene sequences from Madagascar isolates, only two synonymous changes were observed. A SNP at nucleotide 510 (TCC to TCA) was found in one isolate from the Tsiroanomandidy area, whereas an SNP at nucleotide 651 TTA to TTG) was observed in 43 isolates from the other regions [23]. Recently, two synonymous SNPs were found among 84 Korean isolates, four cases has changed nucleotide from $\mathrm{G}$ to $\mathrm{A}$ at base pair 180, two cases has the same nucleotide change at base pair 645 [6]. However, only one kind of synonymous SNP was found at base pair $180(n=5)$ in 25 Korean isolates. SNP at base pair 645 has not been found in this study. It may caused by sample number used in this study. Together with Cho et al [6] and ours data, SNP at base pair 180 is dominant mutation than SNP at base pair 645 in South Korea. Interestingly, mutant strains were isolated from the western part of Han River, which has an approximate length of $514 \mathrm{Km}$.

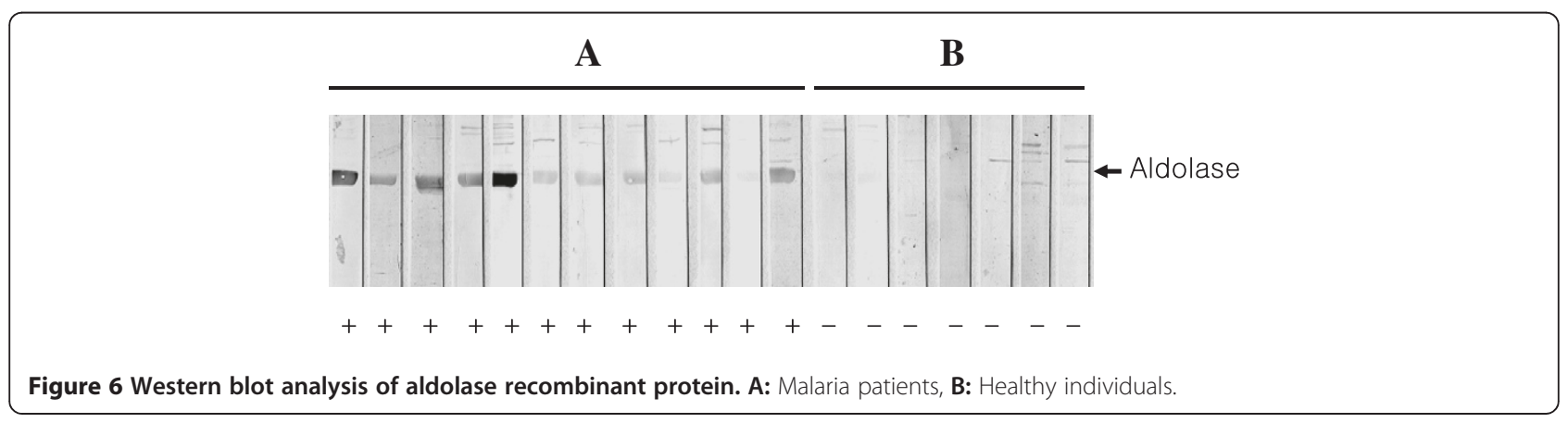




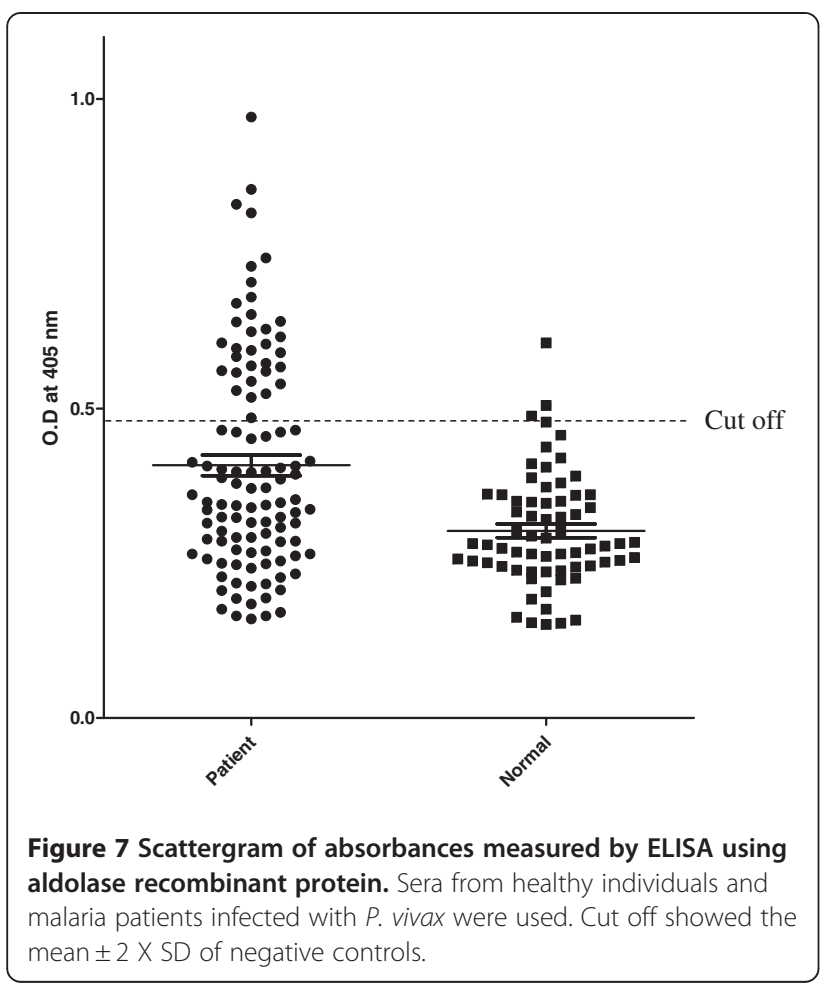

Within the study area, the river is more than $1 \mathrm{Km}$ wide. Therefore, the SNP found in the aldolase gene sequence may be related to the geographical isolation caused by the river. The flight distance a night of Anopheles sinensis, the

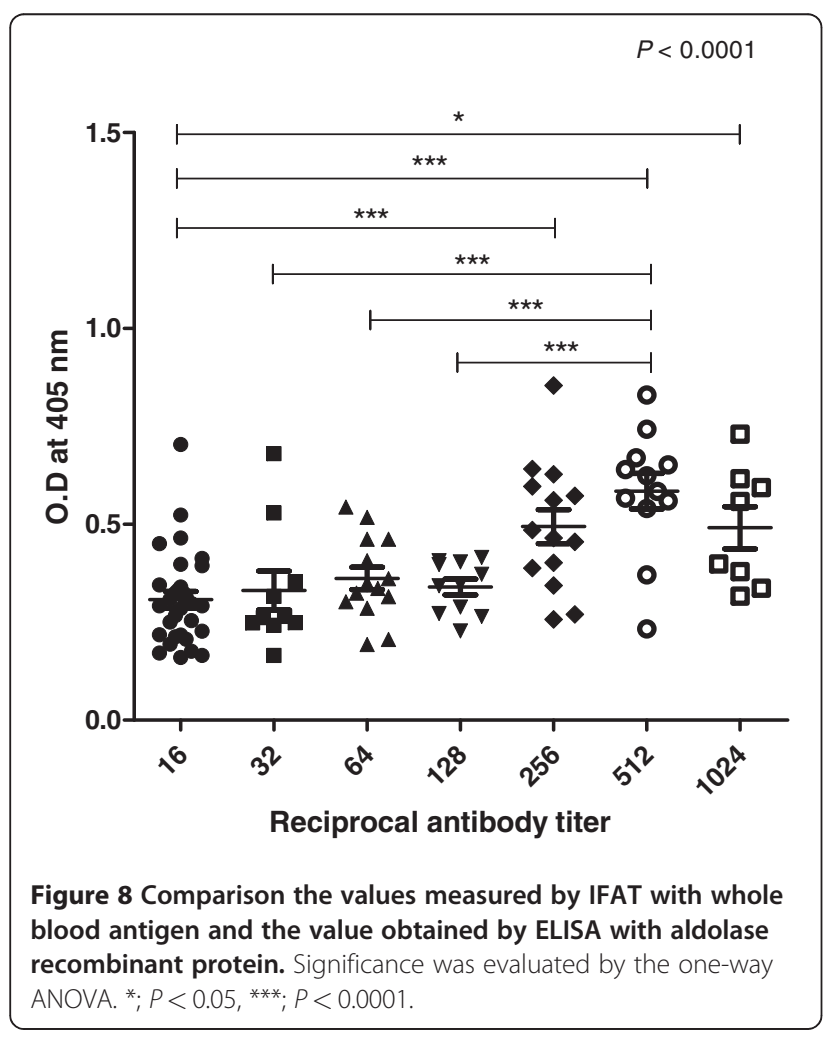

main mosquito vector in Korea, is mainly limited to $1 \mathrm{Km}$ [24], so the river is big enough to prevent mosquitoes crossing the river directly.

Plasmodium vivax has presumably been prevalent in Korea for a long time. However, as a result of a national malaria eradication programme and with help from the $\mathrm{WHO}$, the incidence of vivax malaria has rapidly decreased $[25,26]$. After the latest report of two malaria patients in 1985 [27], there were no additional reported cases until one case was reported in 1993 [28] and two indigenous cases were reported in 1994 [29]. Malaria cases then rapidly increased until around 2000 [30,31]. After that, the reported malaria cases were reduced for several years due to efforts to limit the incidence of malaria. However, malaria was not thoroughly eradicated in the Korean peninsula because $2-3 \%$ of patients experience failed drug treatment every year, and many travellers and workers come from malaria-prevalent areas, including North Korea [32]. For these reasons, serological diagnostic tools are needed to support both traditional microscopic diagnosis and seroepidemiological studies for estimating the prevalence of malaria in Korea. Currently, IFAT is used as the gold standard method due to its high sensitivity. However, the sensitivity might be affected by the ability of examiners. Therefore, a new technique is needed for serodiagnosis. Several recombinant proteins cloned from Korean isolates of $P$. vivax were tested for use as the antigen for serodiagnosis, including circumsporozoite protein (CSP) -subtypes Pv210 [33] and Pv247 [34], merozoite surface protein (MSP) [35], as well as CSP and MSP chimera proteins $[36,37]$. None of these antigens were sufficient to replace the IFAT method, because the sensitivity was less than IFAT. Therefore, it was decided to focus on the enzyme aldolase. Monoclonal antibodies against aldolase were used in several RDTs and showed a relatively high sensitivity in detecting malaria parasites, including Korean isolates [6].

However, the sensitivity of aldolase was 29.4\% (32/109), even though it was cloned from a type of Korean $P$. vivax strain ( $\mathrm{Pv}$ Kor12, Figure 2). There may be many reasons and explanations for the low seroconversion rate detected by ELISA using recombinant aldolase antigen (Figure 7). The same situation happened for the circumsporozoite protein (CSP) of $P$. vivax. The basic reason for the low seroconversion rate for CSP was linked to a low exposure of this developmental stage to dendritic cells. When the seroconversion rate of Korean malaria patients against CSP antigen was analysed, it was shown to be less than $30 \%$. Therefore, a hypothesis was proposed to explain this observation. First, this may be explained by the antigenicity of CSP or the exposure time of contact between DC and CSP before entering the liver cells. Second, it may be explained by the relative short half-life time of CSP antibody in relation to onset time of illness after a long 
incubation period [30,33]. This portion was $70 \%$ and this matches well the portion of antibody positive rate of CSP (30\%) and the percentage of malaria patients who had a short incubation period (30\%). By analogy, this may explain the low seroconversion rate of aldolase. This hypothesis should be tested using blood samples from long and short incubation period patients, but it is not easy to identify patients with long and short incubation periods. Recently, two types of aldolase from $P$. berghei were identified. Aldo-1 was identical to the aldolase gene of P. falciparum and aldo-1 was detected in the sporozoite stage, while aldo- 2 was detected in the asexual stages of malaria parasites [10]. Therefore, it is conceivable that the currently known aldolase of $P$. vivax also belongs to the sporozoite stage. This may explain why recombinant aldolase showed a low seroconversion in this study. Additionally, if the blood stage-specific isoform of aldolase was obtained, it may have much higher seroconversion rate in ELISA.

\section{Conclusions}

The aldolase gene from $P$. vivax Korea isolates has an SNP at 180 (G to A) and, interestingly, the mutant strains were only found along the western part of the Han River. New information of geographic mapping of aldolase at the national or regional scale would provide a valuable aid to developing and updating national anti-malarial policy guidelines in Korea. Additionally, more information is needed before using aldolase as a serological diagnostic antigen.

\section{Competing interests}

The authors declare that they have no competing interests.

\begin{abstract}
Acknowledgments
We are grateful to all of the blood donors and the staff of the Public Health Centers in Gangwha-gun, Gimpo-si, Paju-si, Bucheon-si, and Cheorwon-gun. This work was supported by an internal research grant from the Korean National Institute of Health, Republic of Korea. This work was supported by an internal grant from Korea National Institute of Health, Republic of Korea.
\end{abstract}

\section{Author details}

'Division of Malaria and Parasitic Diseases, National Institute of Health, Korea Centers for Disease Control and Prevention, Cheongwon-gun 363-951, Republic of Korea. 'Vascular Medicine Research Unit, Brigham and Women's Hospital, Harvard Medical School, Cambridge, MA 02139, USA. ${ }^{3}$ Department of Anatomy, College of Oriental Medicine, Institute of Oriental Medicine, Kyung Hee University, Hoegi-dong, Dongdaemun-gu, Seoul 130-701, Republic of Korea. ${ }^{4}$ International Research Center for Bioscience and Biotechnology, Jungwon University, Goesan 367-805, Republic of Korea. ${ }^{5}$ Department of Pathology, University of Florida, J-566, 1275 Center Drive, Gainesville, FL 32610, USA.

\section{Authors' contributions}

JYK, HHK, WJL and HWL conceived and designed the study and contributed to the execution of the research. HWL wrote the manuscript. HHK, SY, and HK contributed statistical analysis. YJK, HIS, and WJL collected the blood samples in the field. YJK, SWL, and HIS performed preparing the DNA samples for DNA sequencing, IFAT and ELISA. All authors have read and approved the final manuscript.
Received: 12 February 2012 Accepted: 8 May 2012

Published: 8 May 2012

\section{References}

1. Reyburn H, Mbatia R, Drakeley C, Carneiro I, Mwakasungula E, Mwerinde O, Saganda K, Shao J, Kitua A, Olomi R, Greenwood BM, Whitty CJ: Overdiagnosis of malaria in patients with severe febrile illness in Tanzania: a prospective study. BMJ 2004, 329:1212.

2. Wongsrichanalai C: Rapid diagnostic techniques for malaria control. Trends Parasitol 2001, 17:307-309.

3. Moody A: Rapid diagnostic tests for malaria parasites. Clinical Microbiol Rev 2002, 15:66-78.

4. Bell D, Peeling RW: Evaluation of rapid diagnostic tests: malaria. Nat Rev Microbiol 2006, 4:S34-S38.

5. Singh N, Saxena A, Valecha N: Field evaluation of the ICT malaria P.f/P.v immunochromatographic test for diagnosis of Plasmodium falciparum and $P$. vivax infection in forest villages of Chhindwara, central India. Trop Med Int Health 2000, 5:765-770.

6. Cho CH, Nam MH, Kim JS, Han ET, Lee WJ, Oh JS, An SS, Lim CS: Genetic variability in Plasmodium vivax aldolase gene in Korean isolates and the sensitivity of the Binax Now malaria test. Trop Med Int Health 2011, 16:223-226

7. Baker J, McCarthy J, Gatton M, Kyle DE, Belizario V, Luchavez J, Bell D, Cheng $\mathrm{Q}$ : Genetic diversity of Plasmodium falciparum histidine-rich protein 2 (PfHRP2) and its effect on the performance of PfHRP2-based rapid diagnostic tests. J Infect Dis 2005, 192:870-877.

8. Lee N, Baker J, Bell D, McCarthy J, Cheng Q: Assessing the genetic diversity of the aldolase genes of Plasmodium falciparum and Plasmodium vivax and its potential effect on performance of aldolase-detecting rapid diagnostic tests. J Clin Microbiol 2006, 44:4547-4549.

9. Talman AM, Duval L, Legrand E, Hubert V, Yen S, Bell D, Le Bras J, Ariey F, Houze S: Evaluation of the intra- and inter-specific genetic variability of Plasmodium lactate dehydrogenase. Malar J 2007, 6:140.

10. Meier B, Döbeli H, Certa U: Stage-specific expression of aldolase isoenzymes in the rodent malaria parasite Plasmodium berghei. Mol Biochem Parasitol 1992, 52:15-27.

11. Barfod A, Persson T, Lindh J: In vitro selection of RNA aptamers against a conserved region of the Plasmodium faciparum erythrocyte membrane protein 1. Parasitol Res 2009, 105:1557-1566.

12. Lee HW, Lee WJ, Lee JS, Lee HS: DNA sequencing and expression of the Circumsporozoite protein of Plasmodium vivax Korean isolate in Escherichia coli. Kor J Microbiol 1999, 37:234-242.

13. Lim KJ, Park JW, Sohn MJ, Lee S, Oh JH, Kim HC, Bahk YY, Kim YS: A direct sandwich ELISA to detect antibodies against the C-terminal region of merozoite surface protein 1 could be a useful diagnostic method to identify Plasmodium vivax exposed persons. Parasitol Res 2002, 88:855-860.

14. Tsang VCW, Peralta JM, Simons AR: Enzyme-linked immunoelectrotransfer blot techniques (EITB) for studying the specificities of antigens and antibodies separated by gel electrophoresis. Meth Enzymol 1983, 92:377-391.

15. Gao YH, Li HL, Lu Y, Gao FM, Lin YH, Zhou HC, Zhang LH, Wang H: Identification of a vaccine candidate antigen, PfMAg-1, from Plasmodium falciparum with monoclonal antibody M26-32. Parasitol Res 2009, 105:1723-1732.

16. Sulzer AJ, Wilson M, Hall EC: Indirect fluorescent antibody tests for parasitic diseases. V. An evaluation of a thick-smear antigen in the IFA test for malaria antibodies. AmJTrop Med Hyg 1969, 18:199-205.

17. Collins WE, Skinner JC: The indirect fluorescent antibody test for malaria. Am Trop Med Hyg 1972, 21:690-695.

18. Collins WE, Warren M, Skinner JC, Fredericks HJ: Studies on the relationship between fluorescent antibody response and ecology of malaria in Malaysia. Bull WHO 1968, 39:451-463.

19. Penhoet E, Rajkumar T, Rutter WJ: Multiple forms of fructose diphosphate aldolase in mammalian tissues. Proc Natl Acad Sci USA 1966, 56:1275-1282.

20. Henze K, Morrsion HG, Sogin ML, Muller M: Sequence and phylogenetic position of a class II aldolase gene in the amitochondriate protist, Giardia lamblia. Gene 1998, 222:163-168.

21. Cloonan N, Fisher K, Cheng Q, Saul A: Aldolase genes of Plasmodium species. Mol Biochem Parasitol 2001, 113:327-330.

22. Clayton CE: Structure and regulated expression of genes encoding fructose biphosphate aldolase in Trypanosoma brucei. EMBO J 1985 4:2997-3003. 
23. Mariette N, Barnadas C, Bouchier C, Tichit M, Menard D: Country-wide assessment of the genetic polymorphism in Plasmodium falciparum and Plasmodium vivax antigens detected with rapid diagnostic test for malaria. Malar J 2006, 7:219.

24. Cho SH, Lee HW, Shin EH, Lee HI, Lee WG, Kim CH, Kim JT, Lee JS, Lee WJ, Jung GG, Kim TS: A mark-release-recapture experiment with Anopheles sinensis in the northern part of Gyeonggi-do, Korea. Kor J Parasitol 2002, 40:139-148.

25. National Malaria Eradication Service: Malaria pre-eradication program in Korea. Progress Report 1961-1965. Republic of Korea: Ministry of Health and Social Affairs; $1966: 44-70$.

26. Paik YH, Ree HI, Shim JC: Malaria in Korea. Jap J Exp Med 1988, 58:55-66.

27. Soh JT, Lee KT, Im Kl, Min DY, Ahn MH, Kim JJ, Yong TS: Current status of malaria in Korea. Yonsei Rep Trop Med 1985, 16:11-18.

28. Chai IH, Lim Gl, Yoon SN, Oh WI, Kim SJ, Chai JY: Occurrence of tertian malaria in a male patient who has never been abroad. Kor J Parasitol 1994, 32:195-200.

29. Cho SY, Kong Y, Park SM, Lee JS, Lim YA, Chae SL, Kho WG, Lee JS, Shim JC, Shin HK: Two vivax malaria cases detected in Korea. Kor J Parasitol 1994, 32:281-284.

30. Lee JS, Kho WG, Lee HW, Seo M, Lee WJ: Current status of vivax malaria among civilians in Korea. Kor J Parasitol 1998, 36:241-248.

31. Park JW, Klein TA, Lee HC, Pacha LA, Ryu SH, Yeom JS, Moon SH, Kim TS, Chai JY, Oh MD, Choe KW: Vivax malaria: a continuing health threat to the Republic of Korea. Am J Trop Med Hyg 2003, 69:159-167.

32. Lee WJ, Kim HH, Choi YK, Choi KM, Kim MA, Kim JY, Sattabongkot J, Sohn Y, Kim H, Lee JK, Park HS, Lee HW: Analysis of the dihydrofolate reductasethymidylate synthase gene sequences in Plasmodium vivax field isolates that failed chloroquine treatment. Malar I 2010, 9:331.

33. Lee HW, Lee JS, Lee WJ, Cho SH, Lee HS: The evaluation of recombinant circumsporozoite protein in malaria diagnosis. Kor J Microbiol 2000, 36:142-149.

34. Kim TS, Kim HH, Lee SS, Oh CM, Choi KM, Lin K, Kim JY, Na BK, Han ET, Sohn Y, Kim H, Lee HW: Molecular cloning and expression of the VK247 circumsporozoite protein for serodiagnosis of variant form Plasmodium vivax. Parasitol Res 2011, 108:1275-1282.

35. Kwon MH, Kim HH, Lee HS, Kim TS, Oh CM, Ahn YJ, Hwang SK, Sohn Y, Kim $\mathrm{H}$, Lee HW: Plasmodium vivax: comparison of the immune responses between oral and parenteral immunization of rPv54 in BALB/c mice. Exp Parasitol 2010, 126:217-223.

36. Lee C, Chung KW, Kim TS, Choi KM, Choi YK, Chung NJ, Rhie HG, Lee HS, Lee SJ, Lee HW: Trials for the co-expression of the merozoite surface protein-1 and circumsporozoite protein genes of Plasmodium vivax. Exp Parasitol 2011, 129:227-233

37. Lee C, Kim HH, Choi KM, Chung KW, Choi YK, Jang MJ, Kim TS, Chung NJ, Rhie HG, Lee HS, Sohn Y, Kim H, Lee SJ, Lee HW: Murine immune responses to a Plasmodium vivax-derived chimeric recombinant protein expressed in Brassica napus. Malar J 2011, 29:106.

doi:10.1186/1475-2875-11-159

Cite this article as: Kim et al:: Genetic variation of aldolase from Korean

isolates of Plasmodium vivax and its usefulness in serodiagnosis. Malaria Journal 2012 11:159.

\section{Submit your next manuscript to BioMed Central and take full advantage of:}

- Convenient online submission

- Thorough peer review

- No space constraints or color figure charges

- Immediate publication on acceptance

- Inclusion in PubMed, CAS, Scopus and Google Scholar

- Research which is freely available for redistribution 